\title{
Elastography in hepatology
}

\author{
Ludovico Abenavoli MD², ${ }^{1,}$ Christophe Corpechot $M D^{2}$, Raoul Poupon MD²
}

L Abenavoli, C Corpechot, R Poupon. Elastography in hepatology. Can J Gastroenterol 2007;21(12):839-842.

\begin{abstract}
A common characteristic of all chronic liver diseases is the occurrence and progression of fibrosis toward cirrhosis. Consequently, liver fibrosis assessment plays an important role in hepatology. Besides its importance for prognosis, determining the level of fibrosis reveals the natural history of the disease and the risk factors associated with its progression, to guide the antifibrotic action of different treatments. Currently, in clinical practice, there are three available methods for the evaluation of liver fibrosis: liver biopsy, which is still considered to be the 'gold standard'; serological markers of fibrosis and their mathematical combination - suggested in recent years to be an alternative to liver biopsy - and, more recently, transient elastography (TE). TE is a new, simple and noninvasive method used to measure liver stiffness. This technique is based on the progressing speed of an elastic shear wave within the liver. Currently, there are only a few studies that have evaluated TE effectiveness in chronic liver diseases, mostly in patients infected with the hepatitis $\mathrm{C}$ virus. Further studies are needed in patients with chronic liver disease, to assess the effectiveness of the fibrosis treatment.
\end{abstract}

Key Words: HCV; Hepatic fibrosis; Liver biopsy; Transient elastography

\section{Élastographie en hépatologie}

Une caractéristique courante de toutes les maladies hépatiques chroniques est l'apparition d'une fibrose qui évolue vers une cirrhose. Par conséquent, l'évaluation de la fibrose hépatique joue un rôle important en hépatologie. Outre son utilité pronostique, la détermination du degré de fibrose révèle l'histoire naturelle de la maladie et les facteurs de risque associés à sa progression afin de suivre l'action antifibrotique de différents traitements. À l'heure actuelle, dans la pratique clinique, on dispose de trois méthodes pour l'évaluation de la fibrose hépatique : la biopsie du foie qui demeure la norme, les marqueurs sérologiques de la fibrose et leurs combinaisons mathématiques, devenus ces récentes années une solution de rechange à la biopsie hépatique, et plus récemment, l'élastographie par impulsions. L'élastographie par impulsions est une nouvelle méthode simple et non effractive utilisée pour mesurer la rigidité du foie. Cette technique se base sur l'analyse du déplacement d'une onde de choc élastique à l'intérieur du foie. À l'heure actuelle, seules quelques études ont évalué l'efficacité de cette technique dans la maladie hépatique chronique, la plupart du temps chez des patients atteints d'hépatite C. D'autres études devront être entreprises chez des patients atteints de maladie hépatique chronique pour évaluer l'efficacité des traitements de la fibrose.
In 1958, Menghini (1) published the first description of liver Ibiopsy (LB) as it pertained to the study of fibrosis. Since then, LB has become the gold standard in the evaluation of liver fibrosis. However, the use of LB has several limitations, including physical and mental discomfort of patients, which may lead to a high percentage of refusals, nonnegligible morbidity and occasional mortality (2). Fibrosis is evaluated by histological semiquantitative scores, among which the METAVIR fibrosis scoring system is the most used (3); it is able to detect different degrees of fibrosis, from absence of fibrosis (FO) to cirrhosis (F4), and shows a better intra- and interobserver reproducibility than other scales (ie, the Knodell, Ishak and Scheuer scales). Histological fibrosis scores do not provide a dynamic picture of the disease, but only information about the diagnosis and prognosis, such as the necroinflammatory activity and the presence of steatosis. Moreover, these scores do not have the power to assess small changes in the degree of liver fibrosis (eg, in the course of an antiviral treatment). This technique is also known to have serious limitations. In one study (4), LB resulted in pain in $24.6 \%$ of the patients, and another study (5) estimated the risk of severe complications to be $3.1 \%$.
Finally, its accuracy in assessing fibrosis is questionable because the reproducibility is poor due to sampling errors, and even in cases of adequately sized specimens, intra- and interobserver discrepancies are found (3-5). In recent years, many research groups have been working to develop noninvasive methods that are capable of detecting and quantifying liver fibrosis. As a result, different biochemical markers of fibrosis, along with their mathematical combinations, have been described in the literature, in particular for chronic hepatitis $\mathrm{C}$ virus (HCV) infections (6). More recently, the assessment of liver fibrosis by a noninvasive method based on physical measurements, called transient elastography (TE) (FibroScan, Echosens, France), has been proposed (7).

\section{ELASTICITY MEASUREMENT}

Elasticity is defined as the ability of a material to deform under the action of a mechanical force. The elasticity of a tissue can be estimated based on the speed of propagation of a transverse shear elastic wave. The higher the speed of propagation of that wave, the higher the stiffness of the tissue. TE measures the speed of propagation in relatively homogenous organs such as

\footnotetext{
${ }^{1}$ Istituto di Medicina Interna, Università Cattolica del S. Cuore, Roma, Italy; ${ }^{2}$ Service d'Hépatologie, Centre national de référence des maladies inflammatoires du foie et des voies biliaires, Hôpital S. Antoine, Paris, France

Correspondence: Dr Ludovico Abenavoli, Istituto di Medicina Interna, Policlinico 'A. Gemelli', Università Cattolica del Sacro Cuore, Largo Gemelli 8, Roma 00168, Italy. Telephone 39-339-866-6533, fax 39-063-550-2775, e-mail l.abenavoli@yahoo.it

Received for publication November 6, 2006. Accepted April 4, 2007
} 
TABLE 1

Advantages and disadvantages of transient elastograpy in hepatology

\begin{tabular}{lc}
\hline Advantages & Disadvantages \\
\hline Simple & The presence of obesity, ascites \\
Noninvasive & and narrow intercostal spaces \\
Rapid & are limiting factors \\
Painless & Available in only a small number \\
Good diagnostic performance for & of centres \\
the absence of fibrosis and cirrhosis & \\
Not influenced by extrahepatic diseases & \\
Correlated with fibrosis area & \\
\hline
\end{tabular}

the liver by using ultrasound pulses to localize the shear elastic wave at different times (7). The measuring device is equipped with a probe consisting of an ultrasonic transducer mounted on the axis of a vibrator. A low-frequency and mild amplitude vibration is transmitted from the vibrator to the tissue by the transducer itself. This vibration induces an elastic shear wave that propagates through the tissue. In the meantime, ultrasonic acquisitions are performed to follow the propagation of the shear wave (7). The propagation speed is defined by the Young modulus and expressed in kilopascals. The probe is applied perpendicularly to the skin (with a small amount of gel film) through one of the right-side intercostal spaces along the midaxillary line. The measurement of the speed is taken along a cylinder of tissue ranging from $25 \mathrm{~mm}$ to $65 \mathrm{~mm}$ of depth under the skin. This corresponds to a volume of liver tissue approximately 100 times larger than that of a LB specimen and represents approximately $1 \%$ of the total organ volume. The examination is noninvasive and can be performed on ambulatory patients in an outpatient setting or at the bedside of a hospitalized patient. TE can be performed by hepatologists or medical staff (physician, resident, medical student or nurse) after a single training session provided by a certified trainer.

Results of the measurements range from $1.3 \mathrm{kPa}$ to $75.4 \mathrm{kPa}$ (7). A panel discussion is in progress to define the number of necessary acquisitions to determine a measurement and the successful percentage required to accept such a measurement (7). Ten acquisitions are considered necessary, with the rate of valid measures always higher than $50 \%$. The intra- and interobserver coefficients of variation are $3.2 \%$ and $3.3 \%$, respectively, indicating very good reproducibility and operator independence (7). The measurement failure rate is between $5 \%$ and $10 \%$, with obesity, ascites or the presence of narrow intercostal spaces considered to be limiting factors $(7,8)$. Elasticity depends mostly on the degree of liver fibrosis, while steatosis and inflammatory activity take on a marginal role in its determination $(9,10)$. TE has been evaluated mostly in patients with chronic HCV infection, with good diagnostic performances for the detection of low-degree liver fibrosis (METAVIR score F0 and F1) and cirrhosis (F4) (Table 1) (9). Access to TE measurement requires a one-time investment in a medical device that is similar to ultrasound equipment. When first developed, TE was used in only a small number of centres, but it is now becoming more common.

\section{ELASTOGRAPHY FOR CHRONIC HCV INFECTION ASSESSMENT}

The statistical analysis of data obtained in large studies on patients with HCV infection shows that elasticity is directly correlated with the degree of hepatic fibrosis. Ziol et al (9)
TABLE 2

Analysis of the transient elastography cut-off point equivalence of the METAVIR fibrosis score*

\begin{tabular}{lcccc}
\hline Variable & $\begin{array}{c}\text { Ziol } \\
\text { et al (9) }\end{array}$ & $\begin{array}{c}\text { Castera } \\
\text { et al (10) }\end{array}$ & $\begin{array}{c}\text { Foucher } \\
\text { et al (14) }\end{array}$ & $\begin{array}{c}\text { Corpechot } \\
\text { et al (19) }\end{array}$ \\
\hline F $\geq 2$ & & & & \\
AUROC & 0.79 & 0.83 & 0.80 & 0.92 \\
Optimal cut-off, kPa & 8.8 & 7.1 & 7.2 & 7.3 \\
Sensitivity, \% & 56 & 67 & 64 & 84 \\
Specificity, \% & 91 & 89 & 85 & 87 \\
PPV, \% & 88 & 95 & 90 & 91 \\
NPV, \% & 56 & 48 & 52 & 79 \\
F $\geq 3$ & & & & \\
AUROC & 0.91 & 0.90 & 0.90 & 0.95 \\
Optimal cut-off, kPa & 9.6 & 9.5 & 12.5 & 9.8 \\
Sensitivity, \% & 86 & 73 & 65 & 91 \\
Specificity, \% & 85 & 91 & 95 & 90 \\
PPV, \% & 71 & 87 & 90 & 84 \\
NPV, \% & 93 & 81 & 80 & 95 \\
F=4 & & & & \\
AUROC & 0.97 & 0.91 & 0.96 & 0.96 \\
Optimal cut-off, kPa & 14.6 & 12.5 & 17.6 & 17.3 \\
Sensitivity, \% & 86 & 87 & 77 & 93 \\
Specificity, \% & 96 & 91 & 97 & 95 \\
PPV, \% & 78 & 77 & 91 & 78 \\
NPV, \% & 97 & 95 & 92 & 99 \\
\hline
\end{tabular}

*The METAVIR fibrosis score ranges from $F=0$ (absence of fibrosis) to $F=4$ (cirrhosis). AUROC Area under the receiver operating characteristic curve; PPV Positive predictive value; NPV Negative predictive value

compared TE with LB in 327 patients with HCV. Based on their chosen trade-offs between sensitivity and specificity, they proposed $8.8 \mathrm{kPa}$ as a cut-off point for a fibrosis score equal to or greater than F2 and $14.6 \mathrm{kPa}$ for cirrhosis (Table 2). The areas under the receiver operating characteristic (ROC) curve were 0.79 (95\% CI 0.73 to 0.84 ) for $\mathrm{F} \geq 2,0.91$ (95\% CI 0.87 to 0.96 ) for $\mathrm{F} \geq 3$, and 0.97 (95\% CI 0.93 to 1) for $\mathrm{F}=4$. A study by Castera et al (10) evaluated the performance of TE in patients with chronic HCV infection, in comparison to and combined with currently available biochemical markers (FibroTest [BioPredictive, France] and the aspartate transaminase in the platelets ratio index [APRI]). LBs were performed on the same day as a reference. The TE and FibroTest diagnostic values were very similar and only slightly better than the APRI score. The detected cut-offs were similar to those described by Ziol et al (9), with $7.2 \mathrm{kPa}$ for $\mathrm{F} \geq 2$ and $12.5 \mathrm{kPa}$ for cirrhosis (F4). The best performance was obtained by combining TE and FibroTest, with areas under the ROC curve of 0.88 ( $95 \%$ CI 0.82 to 0.92 ) for $\mathrm{F} \geq 2,0.95$ for $\mathrm{F} \geq 3$ (95\% CI 0.91 to 0.97 ) and 0.95 for $\mathrm{F}=4$ (95\% CI 0.91 to 0.97) (Table 2). An Italian study (11) compared LB, biochemical markers of fibrosis and TE in $40 \mathrm{HCV}$ infected patients with normal transaminases. The conclusion of that study was that among HCV carriers with normal transaminases, TE was better than FibroTest for the noninvasive detection of fibrosis. Moreover, TE can monitor fibrosis progression in HCV-infected patients subjected to antiviral treatments. Preliminary data from a group of 211 patients treated with pegylated interferon and ribavirin (12) show an important reduction in the elastography values, affirming the antifibrotic action of the therapy, and correlating with the sustained virological 
response. Recently, Carrion et al (13) evaluated the prospective diagnostic accuracy of TE to assess the severity of HCV recurrence after liver transplantation in 124 patients. In that cohort, 169 liver biopsies and 129 hepatic hemodynamic studies were performed to determine the hepatic venous pressure gradient (HVPG). At the same time, patients underwent TE. Liver fibrosis turned out to be mild (F0 to F1) in 96 cases and significant (F2 to F4) in 73 cases. HVPG turned out to be normal (less than $6 \mathrm{mmHg}$ ) in 69 cases and elevated (greater than or equal to $6 \mathrm{mmHg}$ ) in $60(46 \%)$. Using a liver stiffness cut-off value of $8.5 \mathrm{kPa}$ for the diagnosis of fibrosis, $\mathrm{F} \geq 2$ sensitivity, specificity, negative predictive value and positive predictive value were $90 \%, 81 \%, 79 \%$ and $92 \%$, respectively. Areas under the ROC curve for diagnosis of fibrosis greater than or equal to F2, greater than or equal to F3 and equal to F4 were $0.90,0.93$ and 0.98, respectively. There was a close direct correlation between liver stiffness and HVPG, and the area under the ROC curve for diagnosis of portal hypertension was 0.93. Finally, none of the cases with liver stiffness below the cut-off value showed either bridging fibrosis (F3), cirrhosis (F4) or significant portal hypertension (HVPG greater than or equal to $10 \mathrm{mmHg}$ ). The authors concluded that TE is an extremely valuable tool to assess the severity of $\mathrm{HCV}$ recurrence after liver transplantation and reduces the need for follow-up LBs.

\section{OTHER LIVER DISEASES}

Foucher et al (14) evaluated the accuracy of TE in detecting cirrhosis in 711 patients with chronic liver diseases of various etiologies. The results of that study redefined the elastometric cut-off for the diagnosis of hepatic fibrosis stage and, in particular, for the diagnosis of cirrhosis (Table 2). In the same study, the authors identified that the cut-off directly correlated with the presence of complications in cirrhosis; in particular, esophageal varices stage 2 and $3(27.5 \mathrm{kPa})$, Child-Pugh $\mathrm{B}$ and $\mathrm{C}$ cirrhosis $(37.5 \mathrm{kPa})$, past history of ascites $(49.1 \mathrm{kPa})$, hepatocellular carcinoma $(53.7 \mathrm{kPa})$ and variceal bleeding $(62.7 \mathrm{kPa})$. Those data and, in particular, the ability to detect esophageal varices in cirrhotic patients was subsequently confirmed by Kazemi et al (15). In that study, the authors focused on the TE cut-off value for the presence of esophageal varices. One hundred forty patients with cirrhosis underwent both an esophageal endoscopy and a FibroScan trial. They determined that hepatic elasticity values under $20 \mathrm{kPa}$ predicted the absence of second- and third-degree esophageal varices and gastric fundal varices, with a negative predictive value of $99 \%$, which would thus avoid the use of esophagogastroduodenoscopy in $50 \%$ of cases.

The difference in elastometric cut-off for cirrhosis diagnosis reported in the studies by Ziol et al (9), Castera et al (10) and Foucher et al (14) depends on the variability of the study population. Based on an analysis of the data present in the literature, we determined that variations in elastographic cut-off depended on the different liver diseases considered and, consequently, on the different pathological mechanisms that produce the fibrosis. A French multicentre study (16) performed in patients suffering from chronic hepatitis B virus infection reported that the TE accuracy in measuring the fibrosis stage and detecting the presence of cirrhosis was not significantly different from that obtained in patients with chronic HCV. In particular, the area under the ROC curve was 0.81 (95\% CI 0.74 to 0.86 ) for $\mathrm{F} \geq 2,0.92$ (95\% CI 0.86 to 0.95 ) for $\mathrm{F} \geq 3$ and $0.90(95 \%$ CI 0.81 to 0.91$)$ for $F=4$. A study of 245 patients referred to an outpatient alcohol clinic, described a cirrhosis diagnosis value of $13 \mathrm{kPa}$ (17). That study confirmed the TE effectiveness for the diagnosis of cirrhosis; however, it did not confirm the effectiveness of the technique in screening for hepatic fibrosis in very heavy drinkers. In a prospective study, De Ledinghen et al (18) evaluated liver stiffness measurement using TE in 72 HIV-HCV coinfected patients and compared it with other noninvasive methods. In that study, the area under the ROC curve was 0.72 (95\% CI 0.60 to 0.84 ) for $\mathrm{F} \geq 2$ and 0.97 (95\% CI 0.94 to 1.0) for cirrhosis. For the diagnosis of cirrhosis, the optimal cut-off value of liver stiffness was $11.8 \mathrm{kPa}$. Moreover, the study reported the superiority of TE relative to the ratio of aspartate aminotransferase to alanine aminotransferase and relative to the APRI score for a noninvasive diagnosis of virus-related hepatic fibrosis. The authors concluded that liver stiffness measurement is a promising noninvasive method to assess fibrosis in HIV-infected patients with chronic HCV infection. Recently, our research group evaluated TE in cholestatic liver diseases (19), particularly in primary biliary cirrhosis (51 patients) and primitive sclerosing cholangitis (21 patients), detecting the cut-off value to be $7.3 \mathrm{kPa}$ for $\mathrm{F} \geq 2$, $9.8 \mathrm{kPa}$ for $\mathrm{F} \geq 3$ and $17.3 \mathrm{kPa}$ for $\mathrm{F}=4$ (Table 2). The area under the ROC curve was 0.92 (95\% CI 0.87 to 0.98 ) for $\mathrm{F} \geq 2$, 0.95 (95\% CI 0.91 to 0.99 ) for $\mathrm{F} \geq 3$ and 0.96 (95\% CI 0.93 to 1) for $F=4$. These cut-offs were similar to the values described in studies that focused on viral diseases $(9,10)$ and with different etiologies (14) for fibrosis stages $F \geq 2$ and $F \geq 3$. However, regarding cirrhosis $(F=4)$, the cut-off reported in our study is more relevant to the other papers, like in the Foucher et al paper (14). Recently, Ganne-Carrie et al (20) evaluated TE accuracy in detecting cirrhosis in 1257 patients with chronic liver diseases of various etiologies, who were enrolled in a prospective multicentre study. Two hundred fifty patients were excluded because of unsuitable biopsy specimens (132 patients) and unreliable TE measurement (118 patients). Because the study overlapped with a previous one (9), the analysis was performed on 775 new patients, including 120 who were suffering from cirrhosis. The ROC curve analysis was used to assess the diagnostic accuracy. The area under the ROC curve was 0.95 (95\% CI 0.93 to 0.96) in the whole population. The optimal cut-off for the diagnosis of cirrhosis was $14.6 \mathrm{kPa}$ (positive and negative predictive values were $74 \%$ and $96 \%$, respectively), with discrepancies among the etiological groups. This result, compared with other studies, suggests that the cut-off values for the diagnosis of cirrhosis is specific for each etiological group. It can be assumed that this difference is a consequence of discrepancies in fibrosis lesions in different diseases.

TE was performed in 104 children with chronic liver disease, including infants younger than six months of age with a good performance compared with LB (21). The area under the ROC curve was 0.91 (95\% CI 0.79 to 1.0 ) for $\mathrm{F} \geq 2$ and 0.88 (95\% CI 0.75 to 1.0 ) for $F=4$. These data are important in the follow-up of children with chronic liver disease to avoid repeated LBs.

Finally, Laharie et al (22) evaluated liver fibrosis with TE and other noninvasive biochemical methods (FibroTest, APRI and hyaluronate) in 54 Crohn's disease patients treated with methotrexate. Two subgroups of patients were compared: a cumulative dose of methotrexate of more than $1500 \mathrm{mg}$ and methotrexate-naive. Average TE values were similar in the two groups $(5.5 \mathrm{kPa}$ and $4.5 \mathrm{kPa}$, respectively). No significant 
correlation was observed between TE, FibroTest, APRI and hyaluronate values and the cumulative dose of methotrexate. The authors concluded that TE is a reliable, noninvasive method to detect liver fibrosis and could be recommended for such patients.

\section{CONCLUSIONS}

TE is a new, rapid and noninvasive method of fibrosis assessment that offers specialists a new way of supervising patients who are suffering from chronic liver diseases $(6,18)$. TE provides a quantitative operator-independent measurement of liver stiffness. The best known contributor to liver stiffness is the amount of fibrosis; however, recent findings suggest that inflammation, interstitial fluid and even vascular conditions can have an impact on the stiffness measurement obtained by TE. Thus, TE has the potential to provide much more information than just an assessment of fibrosis, and specialists must put the elastographic results in perspective with the rest of their clinical findings. In clinical practice, high TE values

\section{REFERENCES}

1. Menghini G. One-second needle biopsy of the liver. Gastroenterology 1958;35:190-9.

2. Cadranel JF, Rufat P, Degos F. Practices of liver biopsy in France: Results of a prospective nationwide survey. For the Group of Epidemiology of the French Association for the Study of the Liver (AFEF). Hepatology 2000;32:477-81.

3. Bedossa P, Poynard T. An algorithm for the grading of activity in chronic hepatitis C. The METAVIR Cooperative Study Group. Hepatology 1996;24:289-93.

4. Maharaj B, Maharaj RJ, Leary WP, et al. Sampling variability and its influence on the diagnostic yield of percutaneous needle biopsy of the liver. Lancet 1986;1:523-5.

5. Regev A, Berho M, Jeffers LJ, et al. Sampling error and intraobserver variation in liver biopsy in patients with chronic HCV infection. Am J Gastroenterol 2002;97:2614-8.

6. Abenavoli L, Leggio L, Gasbarrini G, Addolorato G. [Evaluation of liver fibrosis in clinical practice.] Recenti Prog Med 2006;97:481-5.

7. Sandrin L, Fourquet B, Hasquenoph JM, et al. Transient elastography: A new noninvasive method for assessment of hepatic fibrosis. Ultrasound Med Biol 2003;29:1705-13.

8. Foucher J, Castera L, Bernard PH, et al. Prevalence and factors associated with failure of liver stiffness measurement using FibroScan in a prospective study of 2114 examinations. Eur J Gastroenterol Hepatol 2006;18:411-2.

9. Ziol M, Handra-Luca A, Kettaneh A, et al. Noninvasive assessment of liver fibrosis by measurement of stiffness in patients with chronic hepatitis C. Hepatology 2005;41:48-54.

10. Castèra L, Vergniol J, Foucher J, et al. Prospective comparison of transient elastography, Fibrotest, APRI, and liver biopsy for the assessment of fibrosis in chronic hepatitis C. Gastroenterology 2005;128:343-50.

11. Colletta C, Smirne C, Fabris C, et al. Value of two noninvasive methods to detect progression of fibrosis among HCV carriers with normal aminotransferases. Hepatology 2005;42:838-45.

12. de Ledinghen V, Castera L, Foucher J, et al. Le FibroScan permet d'aprecier la regression de la fibrose hepatique chez les malades infectes par le VHC repondeurs au traitment par interferon retard may be accurate when assessing the severity of liver disease, detecting the presence of complications and, consequently, providing a follow-up program. In particular, TE allows us to predict the presence of large esophageal varices in patients with cirrhosis and may help to select patients for endoscopic screening $(14,15)$. On the contrary, the role of TE in assessing the hepatocellular carcinoma risk needs further investigation.

Although validated for chronic HCV infection, TE effectiveness will have to be confirmed in other chronic liver diseases, in which specific consensus cut-off has yet to be developed. As a follow-up of liver fibrosis in a treated or nontreated patient, LB is questionable. If the preliminary data that are present in the literature are confirmed, TE would be useful to assess the efficacy of fibrosis treatment. Finally, all other chronic liver diseases, such as chronic cholestatic diseases, alcoholic liver disease, hereditary hemochromatosis, drugrelated iatrogenic chronic conditions or the follow-up after liver transplantation, could benefit from a TE assessment for the diagnosis of fibrosis.

et ribavirine. Etude prospective controlée. Proceedings of $30^{\mathrm{eme}}$ Journees Francophones de pathologie Digestive. Paris: Masson, March 2006.

13. Carrion JA, Navasa M, Bosch J, Bruguera M, Gilabert R, Forns X. Transient elastography for diagnosis of advanced fibrosis and portal hypertension in patients with hepatitis $C$ recurrence after liver transplantation. Liver Transpl 2006;12:1791-8

14. Foucher J, Chanteloup E, Vergniol J, et al. Diagnosis of cirrhosis by transient elastography (FibroScan): A prospective study. Gut 2006;55:403-8.

15. Kazemi F, Kettaneh A, N'kontchou G, et al. Liver stiffness measurement selects patients with cirrhosis at risk of bearing large oesophageal varices. J Hepatol 2006;45:230-5.

16. Marcellin $\mathrm{P}$, de Ledinghen V, Dhumeaux D, et al. Non-invasive assessment of liver fibrosis in chronic hepatitis B using Fibroscan. Hepatology 2005;42(Suppl):715A-6A. (Abst)

17. Melin P, Dacon A, Gauchet A, Schoeny M, Diebold MD. Depistage non invasive de la fibrose-Interet du FibroScan en consultation d'alcoologie. Alcool Addictil 2005;27:191-6.

18. de Ledinghen V, Douvin C, Kettaneh A,, et al. Diagnosis of hepatic fibrosis and cirrhosis by transient elastography in HIV/hepatitis C virus-coinfected patients. J Acquir Immune Defic Syndr 2006;41:175-9.

19. Corpechot C, El Naggar A, Poujol-Robert A, et al. Assessment of biliary fibrosis by transient elastography in patients with $\mathrm{PBC}$ and PSC. Hepatology 2006;43:1118-24.

20. Ganne-Carrie N, Ziol M, de Ledinghen V, et al. Accuracy of liver stiffness measurement for the diagnosis of cirrhosis in patients with chronic liver diseases. Hepatology 2006;44:1511-7.

21. de Ledinghen V, Le Bail B, Rebouissoux L, et al. FibroScan is a new non-invasive method for the diagnosis of liver fibrosis in children A prospective comparison with du Fibrosure and liver biopsy. Hepatology 2005;42(Suppl):472A. (Abst)

22. Laharie D, Zerbib F, Adhoute X, et al. Diagnosis of liver fibrosis by transient elastography (FibroScan) and non-invasive methods in Crohn's disease patients treated with methotrexate. Aliment Pharmacol Ther 2006;23:1621-8. 


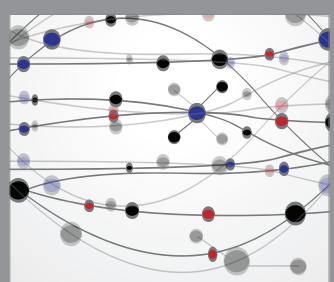

The Scientific World Journal
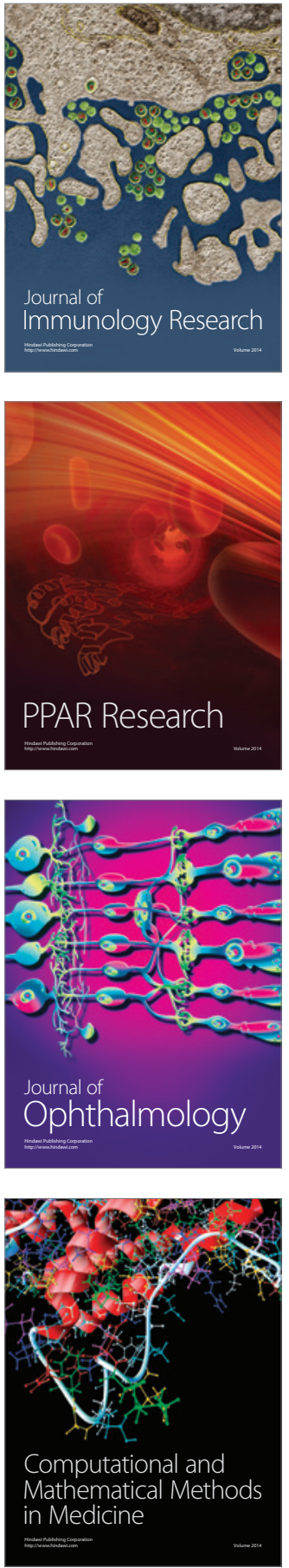

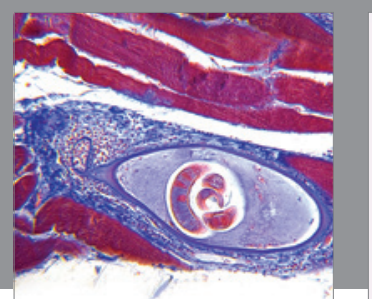

Gastroenterology Research and Practice

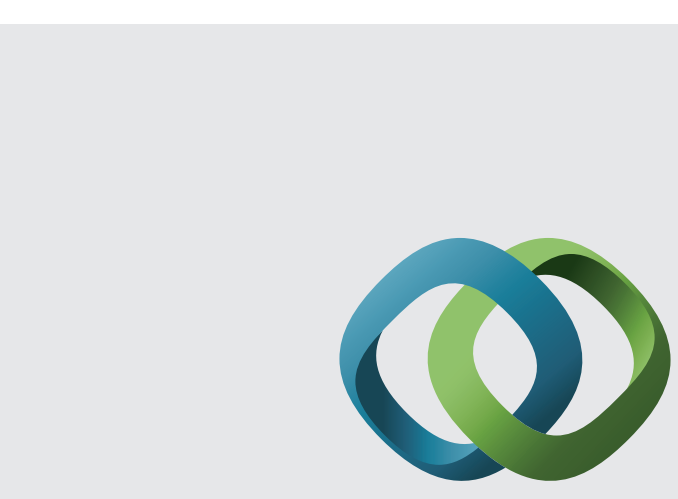

\section{Hindawi}

Submit your manuscripts at

http://www.hindawi.com
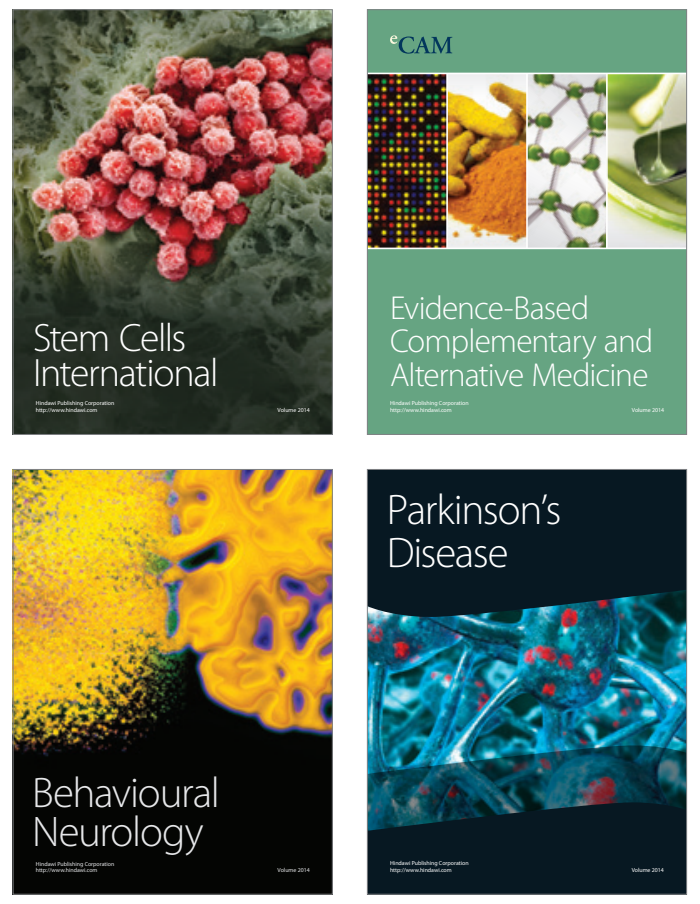
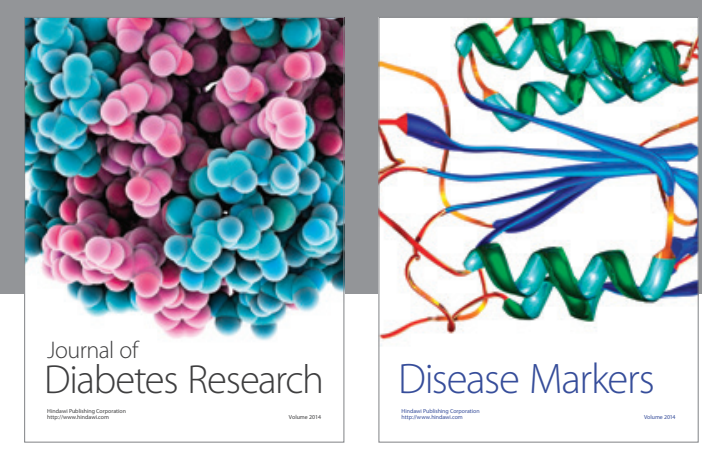

Disease Markers
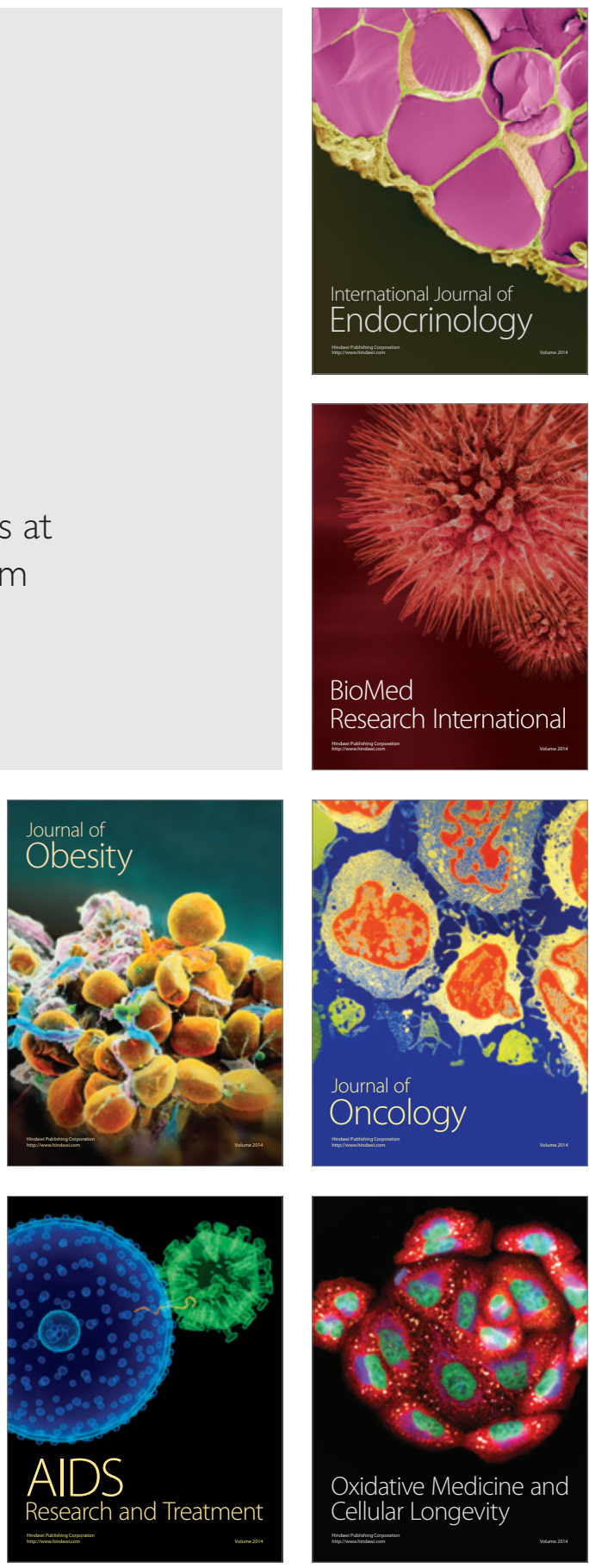